\title{
Metformin and cancer: An existing drug for cancer prevention and therapy (Review)
}

\author{
FUMING ZI ${ }^{1}$, HUAPU ZI ${ }^{2}$, YI LI ${ }^{3}$, JINGSONG HE ${ }^{3}$, QINGZHI SHI ${ }^{1}$ and ZHEN CAI $^{3}$ \\ ${ }^{1}$ Department of Hematology, The Second Affiliated Hospital of Nanchang University, Nanchang, Jiangxi 330008; \\ ${ }^{2}$ Department of Oncology, Rizhao Traditional Chinese Medicine Hospital of Shandong Traditional Chinese Medicine University, \\ Rizhao, Shandong 276800; ${ }^{3}$ Bone Marrow Transplantation Center, The First Affiliated Hospital of \\ Zhejiang University School of Medicine, Hangzhou, Zhejiang 310003, P.R. China
}

Received September 3, 2016; Accepted September 22, 2017

DOI: $10.3892 / \mathrm{ol} .2017 .7412$

\begin{abstract}
Metformin is a standard clinical drug used to treat type 2 diabetes mellitus (T2DM) and polycystic ovary syndrome. Recently, epidemiological studies and meta-analyses have revealed that patients with T2DM have a lower incidence of tumor development than healthy controls and that patients diagnosed with cancer have a lower risk of mortality when treated with metformin, demonstrating an association between metformin and tumorigenesis. In vivo and in vitro studies have revealed that metformin has a direct antitumor effect, which may depress tumor proliferation and induce the apoptosis, autophagy and cell cycle arrest of tumor cells. The mechanism underpinning the antitumor effect of metformin has not been well established. Studies have demonstrated that reducing insulin and insulin-like growth factor levels in the peripheral blood circulation may lead to the inhibition of phosphoinositide 3-kinase/Akt/mechanistic target of rapamycin (mTOR) signaling or activation of AMP-activated protein kinase, which inhibits mTOR signaling, a process that may be associated with the antitumor effect of metformin. The present review primarily focuses on the recent progress in understanding the function of metformin in tumor development.
\end{abstract}

\section{Contents}

1. Introduction

2. Diabetes and cancer: Epidemiological evidence

3. Molecular relationship between diabetes mellitus and tumorigenesis

Correspondence to: Dr Zhen Cai, Bone Marrow Transplantation Center, The First Affiliated Hospital of Zhejiang University School of Medicine, 79 Qingchun Road, Hangzhou, Zhejiang 310003, P.R. China

E-mail: caiz@zju.edu.cn

Key words: metformin, cancer, diabetes, mechanisms
4. Antitumor effect of metformin: Epidemiological evidence

5. Mechanism through which metformin exerts its antitumor effect

6. Combination of metformin and other drugs

7. Influence of metformin on cancer stem cells (CSCs)

8. Conclusion

\section{Introduction}

Tumorigenesis is a chronic process involving numerous factors, including genetic, environmental, life-style and psychological factors. Prophylaxis and etiological treatments are important methods used to control cancer progression. In the early 1930s, Marble (1) first demonstrated the association between diabetes and cancer. Over the past 15 years, an increasing number of studies have demonstrated that the incidence of tumor development is higher in diabetic patients than in healthy controls (2-4), and that cancer patients with diabetes mellitus (DM) are less sensitive to chemotherapy and exhibit a higher risk of mortality (5-10). Epidemiological studies revealed that the incidence of tumorigenesis and the mortality rate of patients with diabetes were significantly reduced in the metformin-treated group compared with that in patients treated with insulin or sulfonylureas (4,10-12). Further studies have demonstrated that metformin has a direct antitumor effect in vivo and in vitro, which may repress the proliferation of tumor cells, and induce apoptosis, autophagy and cell cycle arrest (13-15). Taken together, these results suggest that metformin may become an alternative adjuvant therapy for the treatment of cancer.

\section{Diabetes and cancer: Epidemiological evidence}

In 1934, Marble indicated an association between diabetes and cancer (1). Over the past 15 years, this association has been increasingly recognized, and has become an area of interest for endocrinologists and oncologists. In 2003, Meyerhardt et al (5) observed that colon cancer patients with DM have a higher rate of mortality and tumor recurrence. In 2005, Yang et al (16) reported that the risk of colorectal cancer was increased in type 2 DM (T2DM) patients. Studies have revealed that diabetes is recognized as an independent prognostic factor 
for colon, pancreatic, breast, liver and bladder cancer (6). A meta-analysis revealed that cancer patients with pre-existing diabetes have an increased risk of mortality compared with those without diabetes [hazard ratio (HR), 1.4; $95 \%$ confidence interval (CI), 1.28-1.55] (7). Subgroup analyses revealed an increased risk for certain types of cancer, including endometrial (HR, 1.76; 95\% CI, 1.34-2.31), breast (HR, 1.61; 95\% CI, 1.46-1.78) and colorectal (HR, 1.32; 95\% CI, 1.24-1.41) cancer, respectively. Lee et al (17) reported that, following adjustment for sex, age, hypertension, dyslipidemia and gout, a total of 104,343 Taiwanese patients with diabetes, who were followed up between 1998 and 2009, had an increased incidence of liver, colon, lung, breast cancer and prostate cancer. Furthermore, another meta-analysis demonstrated that patients with diabetes exhibited a $23 \%$ increased risk of breast cancer and a $26 \%$ increased risk of colorectal cancer (18).

Controversy remains regarding the association between diabetes and prostate cancer. A meta-analysis demonstrated that the risk of prostate cancer in patients with diabetes was lower than that in those without diabetes (19). Gong et al (20) also discovered that the risk of prostate cancer was lower in patients with diabetes, when compared with that in those without diabetes. Subsequently, a prospective study of 328,316 males who were followed up for 5 years observed that a history of diabetes is associated with a lower incidence of prostate cancer (21). The biological mechanisms of this association remain unknown, but may be associated with increased physical activity resulting in lower circulating levels of insulin and testosterone, or with changes in the transcription factor 2 hepatic gene (21-24). A multi-ethnic cohort-based prospective study revealed that patients with diabetes were at a lower risk of developing prostate cancer and that this was not associated with their ethnicity (25). However, whether or not the mortality of men with prostate cancer is associated with diabetes remains unknown. It has previously been demonstrated that pre-existing diabetes affects the mortality rate of patients with prostate cancer (25), however this hypothesis is contested by a different study observing no significant association between these two factors (26).

Epidemiological evidence demonstrates an association between diabetes and hematological malignancies $(27,28)$. Using a random-effects model, a meta-analysis of observational studies revealed that T2DM is associated with an increased risk of developing non-Hodgkin's lymphoma, leukemia and myeloma (28). Table I summarizes the meta-analyses of the associations between diabetes and different types of cancer over a number of years (29-41).

\section{Molecular relationship between diabetes mellitus and tumorigenesis}

The mechanisms behind the fact that patients with T2DM are more likely to develop tumors have not yet been fully elucidated. Previous studies have suggested that there are three factors serving important functions in this process.

Insulin resistance. T2DM, which is characterized by insulin resistance and hyperinsulinemia, causes an increased level of insulin and insulin-like growth factor (I/IGF), which could bind to receptors and activate the downstream phosphatidylinositol 3-kinase (PI3K)/Akt and mitogen-activated protein kinase (MAPK) signaling pathways, ultimately leading to the proliferation of cells $(11,37,42-45)$. It has been confirmed that I/IGF and its downstream signaling pathway have an important function in tumor development, and thus, may serve as targets for tumor therapy $(46,47)$. I/IGF signaling pathways are also recognized as playing an important role in the relationship between diabetes and cancer (48).

Diabetes and inflammation. Previously, certain researchers believed diabetes to be an inflammatory disease (49-51). Metabolic disturbances and enhanced oxidative stress in patients with diabetes promote a continuous pro-inflammatory state, resulting in the decreased antioxidant capacity of cells. The insulin resistance that characterizes T2DM may produce large numbers of cytokines, including tumor necrosis factor $\alpha$ (TNF- $\alpha$ ), interleukin (IL)-6 and IL-1 $\beta(49,52)$. TNF- $\alpha$ and IL-6 may activate nuclear factor- $\kappa \mathrm{B}$ and Janus kinase/signal transducer and activator of transcription 3 pathways, which are important signaling pathways in tumorigenesis $(53,54)$.

Hypoimmunity of diabetic patients. Patients with DM are more likely to have persistent infections, suggesting that these patients may be immunodeficient and therefore more susceptible to opportunistic infections (55).

\section{Antitumor effect of metformin: Epidemiological evidence}

In 1957, the FDA approved the use of metformin for the treatment of T2DM. Following this, metformin became recognized as the first-line treatment for diabetes due to its excellent hypoglycemic and cardiovascular protective effects. In 2005, Evans et al (56), in a case-controlled study that included 11,876 T2DM patients, identified for the first time that metformin may reduce the risk of cancer in patients with diabetes (unadjusted odds ratio, 0.79; 95\% CI, 0.67-0.93), and that this effect was positively correlated with the dosage of metformin. In 2006, a population-based retrospective cohort study by Bowker et al (57) revealed that the metformin treatment group had a lower cancer-associated mortality rate compared with that of the sulfonylurea group and the insulin treatment group consisting of other patients with cancer and DM. In 2009, Evans and colleagues re-highlighted the association between metformin treatment and tumorigenesis in patients with T2DM. The tumor incidence in 4,085 patients with diabetes treated with metformin was lower than that in the control group (7.3 vs. $11.6 \%$ ), and the adjusted odds ratio was 0.63 (95\% CI, 0.53-0.75), further demonstrating that metformin may reduce the risk of tumorigenesis (58).

In 2009, a case-controlled study reported by Li et al (59) from the MD Anderson Cancer Center (Houston, TX, USA) revealed that metformin was associated with a reduced risk of pancreatic cancer in patients with diabetes. Compared with those who were not treated with metformin, diabetic patients treated with metformin exhibited an $\sim 62 \%$ reduced risk of developing pancreatic cancer. A retrospective cohort study of 62,809 diabetic patients undertaken by Currie et al (60) demonstrated that monotherapy with metformin was associated with the lowest risk of solid tumor genesis compared 
Table I. Diabetes and tumor risk: Meta-analyses.

\begin{tabular}{lll}
\hline $\begin{array}{l}\text { Tumor characteristic } \\
\text { Tumorigenesis }\end{array}$ & Hazard ratio (95\% CI) & (Refs.) \\
Overall & $1.10(1.04-1.17)$ & $(29)$ \\
Male & $1.14(1.06-1.23)$ & \\
Female & $1.08(1.08-1.28)$ & \\
Tumor type & & \\
Hepatocellular carcinoma & $2.5(1.8-2.9)$ & $(30)$ \\
& $2.01(1.61-2.51)$ & $(31)$ \\
Endometrial cancer & $2.1(1.75-2.53)$ & $(32)$ \\
Colorectal cancer & $1.3(1.2-2.4)$ & $(33)$ \\
Pancreatic cancer & $1.82(1.66-1.89)$ & $(34)$ \\
& $2.1(1.6-2.8)$ & $(35)$ \\
Breast cancer & $1.2(1.12-1.28)$ & $(36)$ \\
& $1.13(0.99-1.28)$ & $(37)$ \\
Prostate cancer & $0.84(0.76-0.93)$ & $(19)$ \\
Bladder cancer & $0.91(0.86-0.96)$ & $(38)$ \\
Non-Hodgkin's lymphoma & $1.3(1.1-1.5)$ & $(39)$ \\
& $1.19(1.04-1.35)$ & $(41)$ \\
\hline
\end{tabular}

CI, confidence interval.

with insulin or sulfonylurea treatment. However, combined treatment with metformin and either insulin or sulfonylurea may reduce the insulin- or sulfonylurea-induced tumor risk. In the aforementioned study, it was observed that, compared with metformin treatment, insulin treatment increased the risk of colorectal and pancreatic cancer, and the HR was 1.69 (95\% CI, 1.23-2.33) and 4.63 (95\% CI, 2.64-8.10), respectively. However, metformin therapy did not reduce the risk of breast or prostate cancer (60).

Another case-controlled study undertaken by Donadon et al (61) demonstrated that treatment with metformin significantly reduced the risk of developing hepatocellular carcinoma (HCC) by $>80 \%$ compared with sulphonylurea and insulin therapy. Additionally, another study revealed that metformin may reduce the risk of $\mathrm{HCC}$ in diabetic patients with chronic liver disease (62).

In 2010, a prospectively-followed cohort study assessed the association between the use of metformin and cancer mortality in 1,353 patients with T2DM (63). Metformin-treated patients were revealed to exhibit a reduced cancer mortality time compared with that of the controls with a median of 9.6 years and an adjusted HR of 0.43 (95\% CI, 0.23-0.80) (63). Diabetic patients taking metformin had a $31 \%$ reduced tumor risk compared with those taking any other antidiabetic drug, particularly for pancreatic cancer and $\mathrm{HCC}$, but not for colon, breast or prostate cancer (64). Jiralerspong et al (65) observed that diabetic patients with breast cancer treated with metformin and neoadjuvant chemotherapy acquired a higher pathological complete response rate than those not being treated with metformin. A nested case-controlled analysis including 22,621 female patients with T2DM demonstrated that patients with diabetes who used metformin for $\geq 5$ years had a decreased risk of developing breast cancer (adjusted odds ratio, 0.44; 95\% CI, 0.24-0.82) (66).

Certain studies have also revealed that diabetic patients with thyroid cancer treated with metformin exhibit a higher rate of remission. Tumor size in the metformin-treated group is significantly smaller than that in the control groups. An in vitro study demonstrated that metformin may activate AMP-inducible protein kinase (AMPK) and downregulate p70S6K/pS6 protein to inhibit the growth of tumor cells (67). Kumar et al (12) revealed that metformin treatment was associated with an improved survival time in patients with ovarian cancer. The progression-free survival time of patients with ovarian cancer and T2DM was longer in the metformin group (68).

Another prospective study (21) and a meta-analysis (19) suggested that pre-existing diabetes may reduce the risk of prostate cancer. Prostate cancer patients with diabetes exhibited a higher rate of mortality compared with those without diabetes (26). Furthermore, Patel et al (69) revealed that prostate cancer patients with diabetes had a higher rate of relapse following prostatectomy, and the use of metformin did not prove to be of any benefit. Additionally, Azoulay et al (70) discovered that the use of metformin did not decrease the risk of prostate cancer in patients with diabetes. These results conflicted with those of Wright and Stanford (71), which observed that metformin may reduce the risk of prostate cancer in patients with diabetes, while He et al (72) suggested that the use of metformin may improve the overall survival of prostate cancer patients with diabetes.

In 2012, Sadeghi et al (73) demonstrated that metformin was associated with an increased survival time in pancreatic cancer patients with diabetes. Furthermore, Noto et al (74) revealed that the use of metformin in patients with diabetes may reduce the risk of cancer incidence and mortality, and indicated that analysis based upon observational studies and long-term randomized controlled trials should be performed to confirm this result. With regards to patients without diabetes, one study discovered that treatment with metformin was associated with a lower risk of colorectal carcinogenesis (75).

\section{Mechanism through which metformin exerts its antitumor effect}

A large volume of epidemiological data has suggested that metformin may benefit cancer patients. In vitro and in vivo experiments have confirmed that metformin may inhibit the proliferation of a variety of tumor cells, but the mechanism underpinning this has not yet been fully elucidated. At present, two major pathways are recognized as the main ways in which metformin exerts its antitumor effect. The first pathway, the I/IGF pathway, may reduce the level of I/IGF-1 in the blood circulation, thereby inactivating its downstream $\mathrm{PI} 3 \mathrm{~K} / \mathrm{Akt} / \mathrm{mTOR}$ signaling pathways to inhibit tumor cell proliferation. The second pathway, the AMPK signaling pathway, may facilitate metformin to directly act on tumor cells, upregulate AMPK and inhibit downstream mTOR (42).

I/IGF and its downstream signaling pathway. I/IGF promote cell mitosis, stimulate cell growth and inhibit cell apoptosis, all of which serve important functions in tumor genesis and 
development (47). Studies in which glyconeogenesis in the liver was reduced have indicated that metformin may effectively reduce blood insulin levels by increasing the sensitivity of surrounding tissue to insulin and inhibiting the intestinal cells from absorbing glucose $(76,77)$. This suggests that metformin may reduce blood insulin levels and may inactivate the I/IGF signaling pathway to exert its antitumor effect. This hypothesis was confirmed by a number of other studies. Goodwin et al (78) demonstrated that, in breast cancer patients without overt $\mathrm{DM}$, the use of metformin may significantly decrease insulin levels and improve insulin resistance. Memmott et al (79) observed that when mice were exposed to the tobacco carcinogen, 4-(methylnitrosamino)-1-(3-pyridyl)-1-butanone, the use of metformin reduced lung tumor burden by up to $53 \%$. This mechanistic study revealed that metformin may directly inhibit mTOR by activating AMPK in liver tissue and may indirectly inhibit mTOR by decreasing activation of insulin receptor/IGF-1 receptor and Akt in lung tissue (79). Algire et al (80) observed that, when colon carcinoma MC38 cells or Lewis lung carcinoma 1 (LLC1) cells were transfected with short hairpin RNA (shRNA) against liver kinase B1 (LKB1), the growth of MC38 and LLC1 cells was significantly inhibited and the phosphorylation of AMPK was markedly increased by metformin in vitro. Additionally, under low-glucose conditions in vitro, MC38 and LLC1 cells transfected with shRNA against LKB1 were more sensitive to metformin. $\mathrm{LKB1}^{+}$and LKB1- MC38 cells were subcutaneously transplanted in the high-fat diet and normal diet mice respectively. The results showed that regardless of the expression of LKB, mice with a high-fat diet were more likely to have tumors, and metformin was able to significantly inhibit insulin levels in high-fat diet mice (80). Pollak (81) demonstrated that, while metformin reduced the insulin level, no effect on the IGF-I/IGF-II level was observed $(47,77,81)$. Karnevi et al (82) demonstrated that metformin may inhibit IGF-IR and activate AMPK in pancreatic cancer cells.

AMPK signaling pathway. AMPK, which is a cellular energy sensor, may be activated by an increased AMP/ATP ratio. Metformin may inhibit the effect of respiratory complex I, leading to reduced oxidative phosphorylation and reduced ATP production, resulting in a reduction in cellular ATP and activation of AMPK (47). In 2006, Zakikhani et al (83) demonstrated that metformin inhibited the proliferation of breast cancer cells through activation of AMPK, leading to the inhibition of mTOR. This growth inhibition was AMPK-dependent and was blocked by small interfering RNA against AMPK (83). There are two pathways known to inhibit mTOR following activation of AMPK. Firstly, AMPK may directly phosphorylate tuberous sclerosis complex 2 (TSC2) on $\mathrm{T} 1227$ and $\mathrm{S} 1345$, and activate the TSC1/TSC 2 compounds, which inhibit the activity of Ras homolog enriched in brain and mTOR (84). Secondly, AMPK directly phosphorylates the mTOR binding partner raptor on 722 and 792 serine residues, which inactivates raptor and mTOR $(85,86)$. Dowling et al $(87)$ revealed that metformin may activate the expression of AMPK, which inhibits phosphorylation of mTOR and its downstream ribosome S6 protein kinase (p70S6K) and eIF4E-binding proteins (4E-BP1). Similarly, other studies observed that the proliferation of cells in leukemia, lymphoma, and prostate, ovarian, colon, endometrial and liver cancer was inhibited by metformin through the AMPK/mTOR pathway (88-93).

Metformin also exerts its antitumor effect in an AMPK-independent manner. Ben Sahra et al (94) reported that metformin may inhibit the cell proliferation and induce the cell-cycle arrest of prostate cancer cell lines by increasing regulated in development and DNA damage response 1 (REDD1) expression in a p53-dependent manner in the absence of AMPK. Inhibition of REDD1 reverses metformin-induced cell-cycle arrest (94). Kalender et al (95) demonstrated that metformin may inhibit mTORC1 in a rag GTPase-dependent manner in the absence of AMPK and TSC1/2. Certain studies have also revealed that metformin may induce the apoptosis and cell-cycle arrest of melanoma cells (96) and epithelial ovarian cancer cell lines (OVCAR-3 and OVCAR-4) (97) in an AMPK-independent manner. Zi et al (98) revealed that metformin may inhibit myeloma cell proliferation through the PI3K/Akt/mTOR signaling pathway, but not through the AMPK/mTOR pathway (98). Taken together, these results demonstrate that metformin exerts an anti-proliferation function through a range of mechanisms.

Whether or not AMPK is an oncogene or a tumor suppressor gene remains to be fully elucidated $(99,100)$. Studies have revealed that AMPK is overactivated in multiple myeloma cells and prostate cancer cells, which may result in cell apoptosis $(101,102)$. At present, metformin is considered to be an AMPK activator by the majority of researchers. However, it is difficult to confirm whether or not metformin is more effective in the treatment of tumors without the functional LKB1-AMPK pathway $(80,103)$. Liu et al (104) observed that, compared with that in normal tissue, AMPK is constitutively activated in human and mouse gliomas (104). However, using an AMPK direct activator, A769662, did not induce glioma cell apoptosis, suggesting that metformin may not exert its antitumor effect through the AMPK pathway (104). Metformin may increase glucose consumption and inhibit the production of ATP in cells. As an 'energy sensor', the activation of AMPK may be a result of cells adapting under survival pressure (80). The authors of the present review hypothesize that when the time or concentration of metformin exposure are increased, cells may have been unable to adapt to compensate for energy deprivation, AMPK phosphorylation may have been suppressed and tumor cell apoptosis may eventually have been induced. Furthermore, it was observed that when AMPK was knocked down, the tolerance of myeloma cells for nutritional deficiency was decreased when compared with that of the control group. Therefore, the effects of metformin on AMPK require further investigation. Fig. 1 summarizes the mechanisms through which metformin exerts its antitumor effect.

\section{Combination of metformin and other drugs}

Combined treatment with metformin may enhance the curative effect of and reduce the adverse reactions associated with chemotherapy. Therefore, combining metformin with traditional chemotherapy drugs has become a novel aspect of cancer therapy. Jiralerspong et al (65) observed that breast cancer patients with DM treated with metformin and neoadjuvant chemotherapy had a higher complete pathological response 


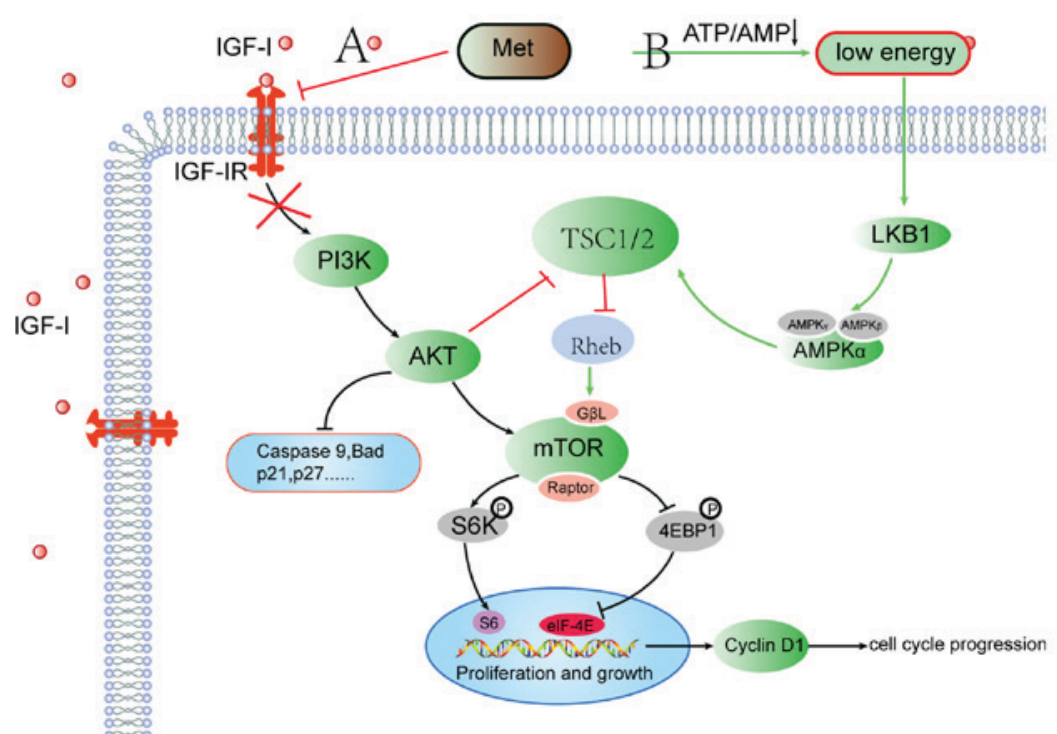

Figure 1. Mechanism through which metformin exerts its antitumor effects (A) by reducing the level of insulin in serum to inhibit the PI3K/Akt/mTOR signaling pathway and (B) by activating AMPK to inhibit the mTOR pathway. P13K, phosphoinositide 3-kinase; mTOR, mechanistic target of rapamycin; AMPK, AMP-activated protein kinase; met, metformin; elF-4E, eukaryotic translation initiation factor 4E; LKB1, liver kinase B1; TSC1/2, tuberous sclerosis proteins 1 and 2 complex; IGF1, insulin-like growth factor 1; IGF1R, IGF1 receptor; 4EBP1, elF-4E-binding protein 1; S6K, ribosomal protein S6 kinase.

rate when compared with the control group (65). Another study reported that this enhanced antitumor effect of chemotherapy may have been due to the inactivation of vitamin B12 induced by metformin through the $\mathrm{N}_{2} \mathrm{O}$ pathway (105). Ben Sahra et al (106) discovered that metformin combined with 2-deoxyglucose (2-DG) may inhibit mitochondrial respiration and glycolysis through tumor protein p53 (p53)-dependent apoptosis via the AMPK pathway. Furthermore, the re-expression of a functional p53 in p53-deficient prostate cancer cells may restore caspase-3 activity (106). A later study observed that combined therapy with metformin and 2-DG may inhibit autophagy and induce AMPK-dependent apoptosis in prostate cancer cells (107). Colquhoun et al (108) revealed that bicalutamide combined with metformin may significantly reduce prostate cancer cell growth compared with single-agent monotherapy. In androgen receptor (AR)-positive cells, this effect appeared to be mediated by enhanced antiproliferation, while the same effect appeared to be mediated by enhanced apoptosis in AR-negative cells (108).

Rocha et al (109) revealed that treating MCF-7 and A549 cells with metformin and paclitaxel markedly inhibited cell viability and increased the number of cells arrested in the G2-M phase of the cell cycle, compared with individual drug treatments, and that the AMPK signaling pathway was involved in this process (109). In an in vivo study, Rattan et al (110) discovered that metformin may inhibit the proliferation, metastasis and angiogenesis of ovarian tumors in xenograft models of A2780 ovarian cancer cells and that it may potentiate cisplatin-induced cytotoxicity by inhibiting tumor growth. Another study observed that, in mouse xenograft models of breast, lung and prostate cancer cell lines, metformin had a synergistic effect when combined with paclitaxel, carboplatin or doxorubicin (111). Metformin also potentiates the effects of paclitaxel by inhibiting the cell proliferation of endometrial cancer cell lines via the mTOR pathway (112). Our previous study also demonstrated that metformin displays anti-myeloma activity and a synergistic effect when combined with dexamethasone in in vitro and in vivo xenograft models (98).

Meanwhile, in an in vitro study, Janjetovic et al (113) demonstrated that metformin reduced the anticancer activity of cisplatin in U251 human glioma, C6 rat glioma, SHSY5Y human neuroblastoma, L929 mouse fibrosarcoma and HL-60 human leukemia cell lines through AMPK-independent upregulation of the Akt pathway.

\section{Influence of metformin on cancer stem cells (CSCs)}

CSCs are considered as one of the causes of tumor resistance and relapse (114-116). Hirsch et al (117) revealed that low doses of metformin may selectively kill breast CSCs (cluster of differentiation (CD) $44^{\text {high }} / \mathrm{CD} 24^{\text {low }}$ ) in four genetically different types of breast cancer (MCF-7, SKBR3, MDA-MB-486 and MCF-10A). Additionally, metformin combined with doxorubicin may kill both CSCs and non-stem cancer cells in vitro, and the remission time was longer when compared with single-agent therapy in a xenograft mouse model (117). A further two studies also demonstrated that metformin may kill breast CSCs $(118,119)$. Shank et al $(120)$ discovered that metformin may restrict the growth and proliferation of ovarian CSCs in vitro and in vivo. Additionally, by re-expressing the miRNAs (let-7a, let-7b, miR-26a, miR-101, miR-200b and miR-200c) that are typically lost in pancreatic cancer and decreasing the expression of CSC-specific genes (including CD44, epithelial cell adhesion molecule, enhancer of zeste homolog 2, Notch-1, Nanog and octamer-binding transcription factor 4), metformin may attenuate the function of CSCs and may be useful for overcoming therapeutic resistance in pancreatic cancer cells (121). Recently, certain studies revealed that metformin may inhibit the growth of prostate and gastrointestinal CSCs (122,123). Florio (124) discovered that metformin selectively inhibits the proliferation of human glioblastoma CSCs through the direct inhibition of chloride intracellular 
channel-1. Therefore, metformin has become recognized as a novel therapeutic option for targeting CSCs $(125,126)$.

\section{Conclusion}

Metformin is the first-line drug for the treatment of T2DM. Epidemiological and basic studies have demonstrated that it may also inhibit the growth of a variety of tumor cells, and an increasing number of ongoing clinical trials on the antitumor activity of metformin are being processed for the treatment of cancer. Metformin has been proven to be safe as a treatment drug for T2DM and has subsequently been used clinically for a number of years. If large-scale clinical trials are able to attest to the antitumor effects of metformin, this drug may become an alternative cancer adjuvant therapy, providing a novel approach for cancer prevention and treatment.

\section{Acknowledgements}

The present study was supported by the National Natural Science Foundation of China (grant no. 81560030), the Natural Science Foundation of Jiangxi Province (grant no. 20151BAB205021), the Natural Science Foundation of Social Development Projects of Jiangxi Province (grant no. 20151BBG70170) and the Health and Family Planning Commission Projects of Jiangxi Province (grant no. 20161066).

\section{References}

1. Marble A: Diabetes and cancer. N Engl J Med 211: 339-349, 1934

2. Simon D: I.15 Diabetes and cancer. Diabetes Res Clin Pract 103 S5, 2014.

3. Pandey A, Forte V, Abdallah M, Alickaj A, Mahmud S, Asad S and McFarlane SI: Diabetes mellitus and the risk of cancer. Minerva Endocrinol 36: 187-209, 2011

4. Lee MS, Hsu CC, Wahlqvist ML, Tsai HN, Chang YH and Huang YC: Type 2 diabetes increases and metformin reduces total, colorectal, liver and pancreatic cancer incidences in Taiwanese: A representative population prospective cohort study of 800,000 individuals. BMC Cancer 11: 20,2011.

5. Meyerhardt JA, Catalano PJ, Haller DG, Mayer RJ, Macdonald JS, Benson AB III and Fuchs CS: Impact of diabetes mellitus on outcomes in patients with colon cancer. J Clin Oncol 21: 433-440, 2003.

6. Coughlin SS, Calle EE, Teras LR, Petrelli J and Thun MJ: Diabetes mellitus as a predictor of cancer mortality in a large cohort of US adults. Am J Epidemiol 159: 1160-1167, 2004.

7. Barone BB, Yeh HC, Snyder CF, Peairs KS, Stein KB, Derr RL, Wolff AC and Brancati FL: Long-term all-cause mortality in cancer patients with preexisting diabetes mellitus: A systematic review and meta-analysis. JAMA 300: 2754-2764, 2008.

8. Rao Kondapally Seshasai S, Kaptoge S, Thompson A, Thompson A, Di Angelantonio E, Gao P, Sarwar N, Whincup PH, Mukamal KJ, Gillum RF, et al: Diabetes mellitus, fasting glucose, and risk of cause-specific death. N Engl J Med 364: 829-841, 2011.

9. Liu X, Ji J, Sundquist K, Sundquist J and Hemminki K: The impact of type 2 diabetes mellitus on cancer-specific survival: A follow-up study in Sweden. Cancer 118: 1353-1361, 2012.

10. Currie CJ, Poole CD, Jenkins-Jones S, Gale EA, Johnson JA and Morgan CL: Mortality after incident cancer in people with and without type 2 diabetes: Impact of metformin on survival. Diabetes Care 35: 299-304, 2012.

11. Vigneri P, Frasca F, Sciacca L, Pandini G and Vigneri R: Diabetes and cancer. Endocr Relat Cancer 16: 1103-1123, 2009.

12. Kumar S, Meuter A, Thapa P, Langstraat C, Giri S, Chien J, Rattan R, Cliby W and Shridhar V: Metformin intake is associated with better survival in ovarian cancer: A case-control study. Cancer 119: 555-562, 2013.
13. Emami Riedmaier A, Fisel P, Nies AT, Schaeffeler E and Schwab M: Metformin and cancer: From the old medicine cabinet to pharmacological pitfalls and prospects. Trends Pharmacol Sci 34: 126-135, 2013.

14. Rizos CV and Elisaf MS: Metformin and cancer. Eur J Pharmacol 705: 96-108, 2013.

15. Bost F, Sahra IB,Le Marchand-Brustel Y and Tanti JF: Metformin and cancer therapy. Curr Opin Oncol 24: 103-108, 2012.

16. Yang YX, Hennessy S and Lewis JD: Type 2 diabetes mellitus and the risk of colorectal cancer. Clin Gastroenterol Hepatol 3: 587-594, 2005.

17. Lee MY, Lin KD, Hsiao PJ and Shin SJ: The association of diabetes mellitus with liver, colon, lung, and prostate cancer is independent of hypertension, hyperlipidemia, and gout in Taiwanese patients. Metabolism 61: 242-249, 2012.

18. Goodwin P: Meta-analysis: Diabetes appears to increase risk, mortality of breast and colon cancers. Oncol Times 35: 33, 2013.

19. Kasper JS and Giovannucci E: A meta-analysis of diabetes mellitus and the risk of prostate cancer. Cancer Epidemiol Biomarkers Prev 15: 2056-2062, 2006.

20. Gong Z, Neuhouser ML, Goodman PJ, Albanes D, Chi C, Hsing AW, Lippman SM, Platz EA, Pollak MN, Thompson IM and Kristal AR: Obesity, diabetes, and risk of prostate cancer: Results from the prostate cancer prevention trial. Cancer Epidemiol Biomarkers Prev 15: 1977-1983, 2006.

21. Calton BA, Chang SC, Wright ME, Kipnis V, Lawson K, Thompson FE, Subar AF, Mouw T, Campbell DS, Hurwitz P, et al: History of diabetes mellitus and subsequent prostate cancer risk in the NIH-AARP Diet and Health Study. Cancer Causes Control 18: 493-503, 2007.

22. Gudmundsson J, Sulem P, Steinthorsdottir V, Bergthorsson JT, Thorleifsson G, Manolescu A, Rafnar T, Gudbjartsson D, Agnarsson BA, Baker A, et al: Two variants on chromosome 17 confer prostate cancer risk, and the one in TCF2 protects against type 2 diabetes. Nat Genet 39: 977-983, 2007.

23. Frayling TM, Colhoun H and Florez JC: A genetic link between type 2 diabetes and prostate cancer. Diabetologia 51: 1757-1760, 2008.

24. Stevens VL, Ahn J, Sun J, Jacobs EJ, Moore SC, Patel AV, Berndt SI, Albanes D and Hayes RB: HNF1B and JAZF1 genes, diabetes, and prostate cancer risk. Prostate 70: 601-607, 2010.

25. Waters KM, Henderson BE, Stram DO, Wan P, Kolonel LN and Haiman CA: Association of diabetes with prostate cancer risk in the multiethnic cohort. Am J Epidemiol 169: 937-945, 2009.

26. Snyder CF, Stein KB, Barone BB, Peairs KS, Yeh HC, Derr RL, Wolff AC, Carducci MA and Brancati FL: Does pre-existing diabetes affect prostate cancer prognosis? A systematic review. Prostate Cancer Prostatic Dis 13: 58-64, 2010.

27. Issa ZA, Zantout MS and Azar ST: Multiple myeloma and diabetes. ISRN Endocrinol 2011: 815013, 2011.

28. Castillo JJ, Mull N, Reagan JL, Nemr S and Mitri J: Increased incidence of non-Hodgkin lymphoma, leukemia, and myeloma in patients with diabetes mellitus type 2: A meta-analysis of observational studies. Blood 119: 4845-4850, 2012.

29. Noto H, Tsujimoto T, Sasazuki T and Noda M: Significantly increased risk of cancer in patients with diabetes mellitus: A systematic review and meta-analysis. Endocr Pract 17: 616-628, 2011.

30. El-Serag HB, Hampel H and Javadi F: The association between diabetes and hepatocellular carcinoma: A systematic review of epidemiologic evidence. Clin Gastroenterol Hepatol 4: 369-380, 2006.

31. Wang C, Wang X, Gong G, Ben Q, Qiu W, Chen Y, Li G and Wang L: Increased risk of hepatocellular carcinoma in patients with diabetes mellitus: A systematic review and meta-analysis of cohort studies. Int J Cancer 130: 1639-1648, 2012.

32. Friberg E, Orsini N, Mantzoros CS and Wolk A: Diabetes mellitus and risk of endometrial cancer: A meta-analysis. Diabetologia 50: 1365-1374, 2007.

33. Larsson SC, Orsini N and Wolk A: Diabetes mellitus and risk of colorectal cancer: A meta-analysis. J Natl Cancer Inst 97: 1679-1687, 2005.

34. Huxley R, Ansary-Moghaddam A, Berrington de González A, Barzi F and Woodward M: Type-II diabetes and pancreatic cancer: A meta-analysis of 36 studies. Br J Cancer 92: 2076-2083, 2005.

35. Everhart J and Wright D: Diabetes mellitus as a risk factor for pancreatic cancer: A meta-analysis. JAMA 273: 1605-1609, 1995.

36. Larsson SC, Mantzoros CS and Wolk A: Diabetes mellitus and risk of breast cancer: A meta-analysis. Int J Cancer 121: 856-862, 2007. 
37. Wolf I, Sadetzki S, Catane R, Karasik A and Kaufman B: Diabetes mellitus and breast cancer. Lancet Oncol 6: 103-111, 2005.

38. Bonovas S, Filioussi K and Tsantes A: Diabetes mellitus and risk of prostate cancer: A meta-analysis. Diabetologia 47: 1071-1078, 2004.

39. Larsson SC, Orsini N, Brismar K and Wolk A: Diabetes mellitus and risk of bladder cancer: A meta-analysis. Diabetologia 49: 2819-2823, 2006.

40. Chao $\mathrm{C}$ and Page JH: Type 2 diabetes mellitus and risk of non-Hodgkin lymphoma: A systematic review and meta-analysis. Am J Epidemiol 168: 471-480, 2008.

41. Mitri J, Castillo J and Pittas AG: Diabetes and Risk of Non-Hodgkin's Lymphoma A meta-analysis of observational studies. Diabetes Care 31: 2391-2397, 2008.

42. Gallagher EJ and LeRoith D: The proliferating role of insulin and insulin-like growth factors in cancer. Trends Endocrino Metab 21: 610-618, 2010.

43. Chowdhury T: Diabetes and cancer. QJM 103: 905-915, 2010.

44. Djiogue S, Nwabo Kamdje AH, Vecchio L, Kipanyula MJ Farahna M, Aldebasi Y and Seke Etet PF: Insulin resistance and cancer: The role of insulin and IGFs. Endocr Relat Cancer 20: R1-R17, 2013.

45. Del Barco S, Vazquez-Martin A, Cufi S, Oliveras-Ferraros C, Bosch-Barrera J, Joven J, Martin-Castillo B and Menendez JA: Metformin: Multi-faceted protection against cancer. Oncotarget 2: 896-917, 2011.

46. Clayton PE, Banerjee I, Murray PG and Renehan AG: Growth hormone, the insulin-like growth factor axis, insulin and cancer risk. Nat Rev Endocrinol 7: 11-24, 2011.

47. Pollak M: The insulin and insulin-like growth factor receptor family in neoplasia: An update. Nat Rev Cancer 12: 159-169, 2012

48. Cohen DH and LeRoith D: Obesity, type 2 diabetes, and cancer: The insulin and IGF connection. Endocr Relat Cancer 19: F27-F45, 2012

49. Donath MY and Shoelson SE: Type 2 diabetes as an inflammatory disease. Nat Rev Immunol 11: 98-107, 2011.

50. Xie W and Du L: Diabetes is an inflammatory disease: Evidence from traditional Chinese medicines. Diabetes Obes Metab 13: 289-301, 2011

51. Cosentino F and Assenza GE: Diabetes and Inflammation. Herz 29: 749-759, 2004.

52. Kern PA, Ranganathan S, Li C, Wood L and Ranganathan G: Adipose tissue tumor necrosis factor and interleukin- 6 expression in human obesity and insulin resistance. Am J Physiol Endocrinol Metab 280: E745-751, 2001

53. Neurath MF and Finotto S: IL-6 signaling in autoimmunity, chronic inflammation and inflammation-associated cancer. Cytokine Growth Factor Rev 22: 83-89, 2011.

54. Waters JP, Pober JS and Bradley JR: Tumour necrosis factor and cancer. J Pathol 230: 241-248, 2013.

55. Geerlings SE and Hoepelman AI: Immune dysfunction in patients with diabetes mellitus (DM). FEMS Immunol Med Microbiol 26: 259-265, 1999.

56. Evans JM, Donnelly LA, Emslie-Smith AM, Alessi DR and Morris AD: Metformin and reduced risk of cancer in diabetic patients. BMJ 330: 1304-1305, 2005.

57. Bowker SL, Majumdar SR, Veugelers P and Johnson JA: Increased cancer-related mortality for patients with type 2 diabetes who use sulfonylureas or insulin. Diabetes Care 29: 254-258, 2006.

58. Libby G, Donnelly LA, Donnan PT, Alessi DR, Morris AD and Evans JM: New users of metformin are at low risk of incident cancer: A cohort study among people with type 2 diabetes. Diabetes Care 32: 1620-1625, 2009.

59. Li D, Yeung SC, Hassan MM, Konopleva M and Abbruzzese JL: Antidiabetic therapies affect risk of pancreatic cancer. Gastroenterology 137: 482-488, 2009.

60. Currie CJ, Poole CD and Gale EA: The influence of glucose-lowering therapies on cancer risk in type 2 diabetes. Diabetologia 52: 1766-1777, 2009.

61. Donadon V, Balbi M, Valent F and Avogaro A: Glycated hemoglobin and antidiabetic strategies as risk factors for hepatocellular carcinoma. World J Gastroenterol 16: 3025-3032, 2010.

62. Donadon V, Balbi M, Mas MD, Casarin P and Zanette G: Metformin and reduced risk of hepatocellular carcinoma in diabetic patients with chronic liver disease. Liver Int 30: 750-758, 2010.

63. Landman GW, Kleefstra N, van Hateren KJ, Groenier KH, Gans RO and Bilo HJ: Metformin associated with lower cancer mortality in type 2 diabetes: ZODIAC-16. Diabetes Care 33: $322-326,2010$
64. Decensi A, Puntoni M, Goodwin P, Cazzaniga M, Gennari A, Bonanni B and Gandini S: Metformin and cancer risk in diabetic patients: A systematic review and meta-analysis. Cancer Prev Res (Phila) 3: 1451-1461, 2010

65. Jiralerspong S, Palla SL, Giordano SH, Meric-Bernstam F, Liedtke C, Barnett CM, Hsu L, Hung MC, Hortobagyi GN and Gonzalez-Angulo AM: Metformin and pathologic complete responses to neoadjuvant chemotherapy in diabetic patients with breast cancer. J Clin Oncol 27: 3297-3302, 2009.

66. Bodmer M, Meier C, Krähenbühl S, Jick SS and Meier CR: Long-term metformin use is associated with decreased risk of breast cancer. Diabetes Care 33: 1304-1308, 2010.

67. Klubo-Gwiezdzinska J, Costello J Jr, Patel A, Bauer A, Jensen K, Mete M, Burman KD, Wartofsky L and Vasko V: Treatment with metformin is associated with higher remission rate in diabetic patients with thyroid cancer. J Clin Endocrinol Metab 98: 3269-3279, 2013

68. Romero IL, McCormick A, McEwen KA, Park S, Karrison T, Yamada SD, Pannain S and Lengyel E: Relationship of type II diabetes and metformin use to ovarian cancer progression, survival, and chemosensitivity. Obstet Gynecol 119: 61-67, 2012

69. Patel T, Hruby G, Badani K, Abate-Shen C and McKiernan JM: Clinical outcomes after radical prostatectomy in diabetic patients treated with metformin. Urology 76: 1240-1244, 2010.

70. Azoulay L, Dell'Aniello S, Gagnon B, Pollak M and Suissa S: Metformin and the incidence of prostate cancer in patients with type 2 diabetes. Cancer Epidemiol Biomarkers Prev 20: 337-344, 2011.

71. Wright JL and Stanford JL: Metformin use and prostate cancer in Caucasian men: Results from a population-based case-control study. Cancer Causes Control 20: 1617-1622, 2009.

72. He XX, Tu SM, Lee MH and Yeung SC: Thiazolidinediones and metformin associated with improved survival of diabetic prostate cancer patients. Ann Oncol 22: 2640-2645, 2011.

73. Sadeghi N, Abbruzzese JL, Yeung SC, Hassan M and Li D Metformin use is associated with better survival of diabetic patients with pancreatic cancer. Clin Cancer Res 18: 2905-2912, 2012.

74. Noto H, Goto A, Tsujimoto $\mathrm{T}$ and Noda M: Cancer risk in diabetic patients treated with metformin: A systematic review and meta-analysis. PLoS One 7: e33411, 2012.

75. Hosono K, Endo H, Takahashi H, Sugiyama M, Sakai E, Uchiyama T, Suzuki K, Iida H, Sakamoto Y, Yoneda K, et al: Metformin suppresses colorectal aberrant crypt foci in a short-term clinical trial. Cancer Prev Res (Phila) 3: 1077-1083, 2010.

76. Freemark M and Bursey D: The effects of metformin on body mass index and glucose tolerance in obese adolescents with fasting hyperinsulinemia and a family history of type 2 diabetes. Pediatrics 107: E55, 2001.

77. Pollak M: Insulin and insulin-like growth factor signalling in neoplasia. Nat Rev Cancer 8: 915-928, 2008.

78. Goodwin PJ, Pritchard KI, Ennis M, Clemons M, Graham M and Fantus IG: Insulin-lowering effects of metformin in women with early breast cancer. Clin Breast Cancer 8: 501-505, 2008.

79. Memmott RM, Mercado JR, Maier CR, Kawabata S, Fox SD and Dennis PA: Metformin prevents tobacco carcinogen-induced lung tumorigenesis. Cancer Prev Res (Phila) 3: 1066-1076, 2010.

80. Algire C, Amrein L, Bazile M, David S, Zakikhani M and Pollak M: Diet and tumor LKB1 expression interact to determine sensitivity to anti-neoplastic effects of metformin in vivo. Oncogene 30: 1174-1182, 2011.

81. Pollak M: Metformin and other biguanides in oncology: Advancing the research agenda. Cancer Prev Res (Phila) 3: 1060-1065, 2010

82. Karnevi E, Said K, Andersson R and Rosendahl AH: Metformin-mediated growth inhibition involves suppression of the IGF-I receptor signalling pathway in human pancreatic cancer cells. BMC Cancer 13: 235, 2013.

83. Zakikhani M, Dowling R, Fantus IG, Sonenberg N and Pollak M: Metformin is an AMP kinase-dependent growth inhibitor for breast cancer cells. Cancer Res 66: 10269-10273, 2006.

84. Inoki K, Zhu T and Guan KL: TSC2 mediates cellular energy response to control cell growth and survival. Cell 115: 577-590, 2003.

85. Gwinn DM, Shackelford DB, Egan DF, Mihaylova MM, Mery A Vasquez DS, Turk BE and Shaw RJ: AMPK phosphorylation of raptor mediates a metabolic checkpoint. Mol Cell 30: 214-226, 2008.

86. Efeyan A and Sabatini DM: mTOR and cancer: Many loops in one pathway. Curr Opin Cell Biol 22: 169-176, 2010. 
87. Dowling RJ,Zakikhani M,Fantus IG, Pollak M and Sonenberg N Metformin inhibits mammalian target of rapamycin-dependent translation initiation in breast cancer cells. Cancer Res 67 10804-10812, 2007.

88. Zakikhani M, Dowling RJ, Sonenberg N and Pollak MN: The effects of adiponectin and metformin on prostate and colon neoplasia involve activation of AMP-activated protein kinase. Cancer Prev Res (Phila) 1: 369-375, 2008.

89. Gotlieb WH, Saumet J, Beauchamp MC, Gu J, Lau S, Pollak MN and Bruchim I: In vitro metformin anti-neoplastic activity in epithelial ovarian cancer. Gynecol Oncol 110: 246-250, 2008.

90. Cantrell LA, Zhou C, Mendivil A, Malloy KM, Gehrig PA and Bae-Jump VL: Metformin is a potent inhibitor of endometrial cancer cell proliferation-implications for a novel treatment strategy. Gynecol Oncol 116: 92-98, 2010.

91. Green AS, Chapuis N, Maciel TT, Willems L, Lambert M, Arnoult C, Boyer O, Bardet V, Park S, Foretz M, et al: The LKB1/AMPK signaling pathway has tumor suppressor activity in acute myeloid leukemia through the repression of mTOR-dependent oncogenic mRNA translation. Blood 116: 4262-4273, 2010.

92.Zheng L, Yang W, Wu F, Wang C, Yu L, Tang L, Qiu B, Li Y, Guo L, Wu M, et al: Prognostic significance of AMPK activation and therapeutic effects of metformin in hepatocellular carcinoma. Clin Cancer Res 19: 5372-5380, 2013.

93. Shi WY, Xiao D, Wang L, Dong LH, Yan ZX, Shen ZX, Chen SJ, Chen Y and Zhao WL: Therapeutic metformin/AMPK activation blocked lymphoma cell growth via inhibition of mTOR pathway and induction of autophagy. Cell Death Dis 3: e275, 2012.

94. Ben Sahra I, Regazzetti C, Robert G, et al: Metformin, independent of AMPK, induces mTOR inhibition and cell-cycle arrest through REDD1. Cancer Res 71: 4366-4372, 2011.

95. Kalender A, Selvaraj A, Kim SY, Gulati P, Brûlé S, Viollet B, Kemp BE, Bardeesy N, Dennis P, Schlager JJ, et al: Metformin, independent of AMPK, inhibits mTORC1 in a rag GTPase-dependent manner. Cell Metab 11: 390-401, 2010.

96. Janjetovic K, Harhaji-Trajkovic L, Misirkic-Marjanovic M, Vucicevic L, Stevanovic D, Zogovic N, Sumarac-Dumanovic M, Micic D and Trajkovic V: In vitro and in vivo anti-melanoma action of metformin. Eur J Pharmacol 668: 373-382, 2011.

97. Yasmeen A, Beauchamp MC, Piura E, Segal E, Pollak M and Gotlieb WH: Induction of apoptosis by metformin in epithelial ovarian cancer: Involvement of the Bcl-2 family proteins. Gynecol Oncol 121: 492-498, 2011.

98. Zi FM, He JS, Li Y, Wu C, Yang L, Yang Y, Wang LJ, He DH, Zhao Y, Wu WJ, et al: Metformin displays anti-myeloma activity and synergistic effect with dexamethasone in in vitro and in vivo xenograft models. Cancer Lett 356: 443-453, 2015.

99. Liang J and Mills GB: AMPK: A contextual oncogene or tumor suppressor? Cancer Res 73: 2929-2935, 2013.

100. Hardie DG: The LKB1-AMPK pathway-friend or foe in cancer? Cancer Cell 23: 131-132, 2013.

101. Park HU, Suy S, Danner M, Dailey V, Zhang Y, Li H, Hyduke DR, Collins BT, Gagnon G, Kallakury B, et al: AMP-activated protein kinase promotes human prostate cancer cell growth and survival. Mol Cancer Ther 8: 733-741, 2009.

102. Baumann P, Mandl-Weber S, Emmerich B, Straka C and Schmidmaier R: Inhibition of adenosine monophosphate-activated protein kinase induces apoptosis in multiple myeloma cells. Anticancer Drugs 18: 405-410, 2007.

103. Shackelford DB, Abt E, Gerken L, Vasquez DS, Seki A, Leblanc M, Wei L, Fishbein MC, Czernin J, Mischel PS and Shaw RJ: LKB1 inactivation dictates therapeutic response of non-small cell lung cancer to the metabolism drug phenformin. Cancer Cell 23: 143-158, 2013.

104. Liu X, Chhipa RR, Pooya S, Wortman M, Yachyshin S, Chow LM, Kumar A, Zhou X, Sun Y, Quinn B, et al: Discrete mechanisms of mTOR and cell cycle regulation by AMPK agonists independent of AMPK. Proc Natl Acad Sci USA 111: E435-E444, 2014.

105. Garcia A and Tisman G: Metformin, B(12), and enhanced breast cancer response to chemotherapy. J Clin Oncol 28: e19-e20, 2010

106. Ben Sahra I, Laurent K, Giuliano S, Larbret F, Ponzio G, Gounon P, Le Marchand-Brustel Y, Giorgetti-Peraldi S, Cormont M, Bertolotto $\mathrm{C}$, et al: Targeting cancer cell metabolism: The combination of metformin and 2-deoxyglucose induces p53-dependent apoptosis in prostate cancer cells. Cancer Res 70: 2465-2475, 2010.

107. Ben Sahra I, Tanti JF and Bost F: The combination of metformin and 2 deoxyglucose inhibits autophagy and induces AMPK-dependent apoptosis in prostate cancer cells. Autophagy 6: 670-671, 2010.
108. Colquhoun AJ, Venier NA, Vandersluis AD, Besla R, Sugar LM, Kiss A, Fleshner NE, Pollak M, Klotz LH and Venkateswaran V: Metformin enhances the antiproliferative and apoptotic effect of bicalutamide in prostate cancer. Prostate Cancer Prostatic Dis 15: 346-352, 2012.

109. Rocha GZ, Dias MM, Ropelle ER, Osório-Costa F, Rossato FA, Vercesi AE, Saad MJ and Carvalheira JB: Metformin amplifies chemotherapy-induced AMPK activation and antitumoral growth. Clin Cancer Res 17: 3993-4005, 2011.

110. Rattan R, Graham RP, Maguire JL, Giri S and Shridhar V: Metformin suppresses ovarian cancer growth and metastasis with enhancement of cisplatin cytotoxicity in vivo. Neoplasia 13: 483-491, 2011.

111. Iliopoulos D, Hirsch HA and Struhl K: Metformin decreases the dose of chemotherapy for prolonging tumor remission in mouse xenografts involving multiple cancer cell types. Cancer Res 71: 3196-3201, 2011

112. Hanna RK, Zhou C, Malloy KM, Sun L, Zhong Y, Gehrig PA and Bae-Jump VL: Metformin potentiates the effects of paclitaxel in endometrial cancer cells through inhibition of cell proliferation and modulation of the mTOR pathway. Gynecol Oncol 125: 458-469, 2012.

113. Janjetovic K, Vucicevic L, Misirkic M, Vilimanovich U, Tovilovic G, Zogovic N, Nikolic Z, Jovanovic S, Bumbasirevic V, Trajkovic V and Harhaji-Trajkovic L: Metformin reduces cisplatin-mediated apoptotic death of cancer cells through AMPK-independent activation of Akt. Eur J Pharmacol 651: $41-50,2011$

114. Donnenberg VS and Donnenberg AD: Multiple drug resistance in cancer revisited: The cancer stem cell hypothesis. J Clin Pharmacol 45: 872-877, 2005

115. Eyler CE and Rich JN: Survival of the fittest: Cancer stem cells in therapeutic resistance and angiogenesis. J Clin Oncol 26: 2839-2845, 2008

116. Clevers H: The cancer stem cell: Premises, promises and challenges. Nat Med 17: 313-319, 2011

117. Hirsch HA, Iliopoulos D, Tsichlis PN and Struhl K: Metformin selectively targets cancer stem cells, and acts together with chemotherapy to block tumor growth and prolong remission. Cancer Res 69: 7507-7511, 2009.

118. Cufi S, Corominas-Faja B, Vazquez-Martin A, Oliveras-Ferraros C, Dorca J, Bosch-Barrera J, Martin-Castillo B and Menendez JA: Metformin-induced preferential killing of breast cancer initiating CD44+CD24-/low cells is sufficient to overcome primary resistance to trastuzumab in HER2+ human breast cancer xenografts. Oncotarget 3: 395-398, 2012.

119. Song CW, Lee H, Dings RP, Williams B, Powers J, Santos TD, Choi BH and Park HJ: Metformin kills and radiosensitizes cancer cells and preferentially kills cancer stem cells. Sci Rep 2: $362,2012$.

120. Shank JJ, Yang K, Ghannam J, Cabrera L, Johnston CJ, Reynolds RK and Buckanovich RJ: Metformin targets ovarian cancer stem cells in vitro and in vivo. Gynecol Oncol 127: 390-397, 2012

121. Bao B, Wang Z, Ali S, Ahmad A, Azmi AS, Sarkar SH, Banerjee S, Kong D, Li Y, Thakur S and Sarkar FH: Metformin inhibits cell proliferation, migration and invasion by attenuating CSC function mediated by deregulating miRNAs in pancreatic cancer cells. Cancer Prev Res (Phila) 5: 355-364, 2012.

122. Mayer MJ, Klotz LH and Venkateswaran V: Metformin and prostate cancer stem cells: A novel therapeutic target. Prostate Cancer Prostatic Dis 18: 303-309, 2015.

123. Di Francesco AM, Toesca A, Cenciarelli C, Giordano A, Gasbarrini A and Puglisi MA: Metabolic modification in gastrointestinal cancer stem cells: Characteristics and therapeutic approaches. J Cell Physiol 231: 2081-2087, 2016.

124. Florio T: Antitumoral effects of metformin on cancer stem cells Ann d'Endocrinologie 76: 296, 2015.

125. Rattan R, Ali Fehmi R and Munkarah A: Metformin: An emerging new therapeutic option for targeting cancer stem cells and metastasis. J Oncol 2012: 928127, 2012.

126. Bednar F and Simeone DM: Metformin and cancer stem cells: Old drug, new targets. Cancer Prev Res (Phila) 5: 351-354, 2012. 